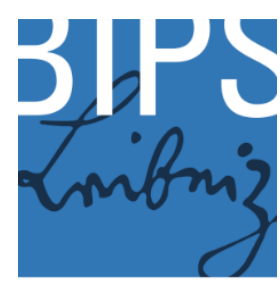

Leibniz Institute

for Prevention Research and

Epidemiology-BIPS

\title{
HPV infection awareness and self-reported HPV vaccination coverage in female adolescent students in two German cities
}

Florence Samkange-Zeeb, Lena Spallek, Stefanie J. Klug, Hajo Zeeb

DOI

10.1007/s10900-012-9589-1

\section{Published in}

Journal of Community Health

Document version

Accepted manuscript

This is the author's final accepted version. There may be differences between this version and the published version. You are advised to consult the publisher's version if you wish to cite from it.

\section{Online publication date}

7 July 2012

\section{Corresponding author}

Florence Samkange-Zeeb

\section{Citation}

Samkange-Zeeb F, Spallek L, Klug SJ, Zeeb H. HPV infection awareness and self-reported HPV vaccination coverage in female adolescent students in two German cities. J Community Health. 2012;37(6):1151-6.

This is a post-peer-review, pre-copyedit version of an article published in the Journal of Community Health. The final authenticated version is available online at:

http://dx.doi.org/10.1007/s10900-012-9589-1. 


\begin{abstract}
Background: Low levels of human papillomavirus (HPV) awareness and knowledge have been observed in the few studies conducted among school-going adolescents. Such data are lacking in Germany.
\end{abstract}

Aim: To assess awareness of HPV and of vaccination status among girls attending grades 8-13 in Bremen and Bremerhaven, two German cities.

Methods: Participants completed a questionnaire in school including questions on demographic characteristics, about HPV awareness and on vaccination status. We analysed the relationship between awareness of HPV, of vaccination status and vaccine uptake and several variables including age and migrant background using univariate and multivariate logistic regression.

Results: Six hundred and thirty-two girls aged 12-20 years completed the questionnaire. $50 \%$ had no awareness of HPV, 12\% reported being vaccinated against HPV and 57\% did not know whether or not they were vaccinated against HPV. In multivariate analyses, ever had sex was significantly associated with awareness of HPV, and ever been to a gynaecologist with awareness of own vaccination status.

Conclusion: Our results may be an indication that female adolescents in Germany are not adequately informed and counselled about HPV and associated issues.

Key words: HPV awareness, Vaccination status, Adolescents 


\section{HPV infection awareness and self-reported HPV vaccination coverage in female adolescent students in two German cities}

Samkange-Zeeb F ${ }^{1}$, Spallek L ${ }^{1}$, Klug $\mathrm{SJ}^{2}$, Zeeb $\mathrm{H}^{1}$.

${ }^{1}$ BIPS - Institut für Epidemiologie und Präventionsforschung GmbH

${ }^{2}$ Cancer Epidemiology, University Cancer Center, Technical University Dresden

\section{Correspondence:}

Florence Samkange-Zeeb, MPH (Scientist)

BIPS - Institute for Epidemiology and Prevention Research

Achterstrasse 30

D-28359 Bremen

Germany

Tel: $+49(0) 421218-56981$

Fax: $+49(0) 421218-56941$

Email: samkange@bips.uni-bremen.de

${ }^{1}$ Lena Spallek, BSc (Scientist)

Email: 1spallek@bips.uni-bremen.de

${ }^{2}$ Stefanie J Klug, Professor (Head of Dept.)

Email: Stefanie.Klug@uniklinikum-dresden.de

${ }^{1}$ Hajo Zeeb, Professor (Head of Dept.)

Email: zeeb@bips.uni-bremen.de 


\section{Introduction}

Human papillomavirus (HPV) is one of the most common sexually transmitted infections and a known causal risk factor for cervical cancer (Walboomers et al. 1999). In 2006 and 2007 the European Commission licensed two vaccines against HPV, which have since been introduced in many countries. In Germany, the vaccine is recommended for girls aged 12-17 years (STIKO 2007).

Numerous studies on knowledge on HPV, awareness and acceptance of the vaccine were conducted mostly among adults before and around the time the vaccines were introduced. These studies generally observed low levels of HPV awareness and knowledge ranging from 3.4\% to 53\% (Klug et al. 2005; Marlow et al. 2007; Ogilvie et al. 2007; Lenselink et al. 2008; Walsh et al., 2008). Few studies have assessed awareness and knowledge of HPV among school-going adolescents. As among adults, low levels of awareness and knowledge between 5.4\% and 66\% have been observed (Woodhall et al. 2007; Höglund et al. 2009; Agius et al. 2010; Marek et al. 2011). Awareness has been reported to be higher among females than among males: $16.4 \%$ vs. 9.6\% in a Swedish study (Gottvall et al. 2009), 71.6\% vs. 51.2\% in an Italian study (Pelucchi et al. 2010), and 50\% vs. 30\% among secondary school pupils in Hungary (Marek et al. 2011).

In Germany these issues have yet to be assessed among school-going adolescents. In a recent survey conducted among 18-25 year old vocational school students in Berlin, only 52\% of the women and $25.3 \%$ of the young men had ever heard of HPV (Blödt et al. 2011).

Varying HPV vaccine uptake rates have been reported in Europe. During the first year of the vaccination programme, the coverage of the three doses among eligible girls was reported to be about 44\% in Belgium (Simoens et al. 2009), 53.1\% in Italy and 77.3\% in Spain (Limia 2011), and $80.9 \%$ in the United Kingdom (Sheridan et al., 2010). According to estimates based on data from health insurance companies, less than $20 \%$ of 17 year old girls in Germany were vaccinated in 2008 (Zylka-Menhorn and Meyer 2009), and the proportions were even lower among younger girls.

We assessed whether factors such as age, migrant background, sexual activity and visit to a gynaecologist are associated with awareness of HPV, of HPV vaccination status and selfreported vaccine uptake among female pupils. The data were collected in the context of a survey to assess awareness, knowledge and practices on sexually transmitted diseases among school pupils attending the $8^{\text {th }}$ grade and above. 


\section{Methods}

\section{Recruitment of schools and pupils}

The study was conducted between October and December 2011 among 12-20 year old adolescents attending the $8^{\text {th }}$ grade and above in secondary schools in two cities Bremen and Bremerhaven, located in the north of Germany. The principals of 18 randomly selected government secondary schools were contacted and asked for permission to conduct our survey in their schools. Eight schools (6 in Bremen und 2 in Bremerhaven) agreed to co-operate. The schools are located in different areas of the two cities and included the two school forms offered in the region: schools offering up to the $10^{\text {th }}$ grade and those offering up to the $12^{\text {th }}$ or $13^{\text {th }}$ grade. The teachers, parents of the pupils, as well as the pupils themselves were provided with written information, including consent forms, about the study. Information for parents was also provided in Turkish and Russian. Pupils younger than 18 years old had to have signed parental consent for them to take part in the survey. According to data protection regulations, pupils $\geq 18$ years could not give information on parents' education without signed consent of the parents.

The study was approved by the ethics committee of the University of Bremen, the Senator for Education, Science and Health, and the Data Protection Officer for the State of Bremen.

\section{Questionnaire}

Pupils with signed consent completed an anonymous, self-administered questionnaire at their school. The pupils were asked to indicate whether they had ever heard about HPV and whether vaccination is possible. They were also asked if they had ever had sex, ever been to a gynaecologist, if they had ever heard of cervical cancer and the virus associated with it, and if they had been vaccinated against HPV. The items ever heard of HPV, aware that HPV can cause cervical cancer and aware of HPV vaccination possibility were combined to form the outcome variable awareness of HPV.

Although frequency of sexual partners and use of contraception were also measured, these were not included in the present analyses. Socio-demographic information such as age, country of birth and parents' educational level was also collected.

For the last variable, three levels were created according to the International Standard Classification of Education (ISCED): 'low'= levels $0-2$, 'medium'=3-4 and 'high' $\geq 5$ (UNESCO 2010).

\section{Analysis}

Data analyses were conducted using SAS version 9.2. We performed descriptive statistics and 
calculated frequencies for all variables. After reviewing the distribution of the frequencies for the outcome variable awareness of HPV, two categories were built for the variable: no awareness (no question on awareness positively answered) and some awareness (at least one question positively answered). The variable school education of father was not included in the analyses as there were many missing values. For the independent variable school education of mother, the levels 'low' and 'medium' were combined as the number of observations in the former group was very low. Using univariate logistic regression, we analysed the relationship between the three outcome variables, awareness of HPV, awareness of vaccination status and self-reported vaccine uptake, and each of the following variables: age, migrant background, school education of mother, ever had sex, ever having been to a gynaecologist. Multivariable logistic regression analyses were initially conducted including independent variables which were statistically significant in univariate analyses. For the variable awareness of HPV, regression analyses were also conducted comparing the two extreme groups: the group of pupils with no awareness versus those who positively answered at least two items. 


\section{Results}

There were 2,049 girls registered in the 8 participating schools at the time of the survey, 418 $(20 \%)$ of whom were recorded in the school statistics as having a migrant background (defined as language other than German spoken at home). A total of 632 (31\%) girls completed the questionnaire. Of these, 201 (32\%) had a migrant background, 46\% were younger than 15 years old and $53 \%$ were in the $8^{\text {th }}$ and $9^{\text {th }}$ grade (table 1). Of all the demographic items included in the questionnaire, the one with the highest proportion of missing values, respectively 'Don't know' responses was parental education (table 1). More than $50 \%$ of pupils aged $\geq 18$ years did not give information on parents' education as they did not have signed parental consent to do so. However, the highest proportion of pupils who reported that they did not know their parents' school education level was among those younger than 15 years old.

Although $94 \%$ of the girls had heard of cervical cancer, almost 50\% did not positively answer any of the items on awareness of HPV, 27\% positively answered one item, 14\% two items, and only $9 \%$ positively answered all 3 items (data not shown). Fifty-two per cent of the pupils with no awareness of HPV were 12-14 years old and 80\% had never had sex. The distribution of pupils according to migrant background was similar among those with no awareness and those with some awareness of HPV: $67 \%$ without and $32 \%$ with migrant background (table 1).

All in all, 12\% of the girls reported being vaccinated against HPV and 57\% did not know whether or not they had been vaccinated against HPV (table 1). Of those who reported being vaccinated against HPV, 69\% were 15 years and older and 31\% had a migrant background. Forty-one per cent reported ever having had sex and almost three-quarters had been to a gynaecologist (table 1).

Of the 361 girls who did not know whether or not they were vaccinated against HPV, more than $50 \%$ were $\leq 14$ years old and $36 \%$ had a migrant background. Eighty per cent had never had sex and $56 \%$ had never been to a gynaecologist (table 1 ).

\section{Awareness of HPV}

Older age, ever had sex, having been to a gynaecologist and awareness of vaccination status were significantly associated with awareness of HPV in univariate analyses. Similar results were observed when comparing pupils with no awareness to those with some awareness (at least one positively answered awareness item) and when comparing them to those with at least two positively answered awareness items. In both instances, only the variable ever had sex remained 
statistically significant in multivariate analyses (tables 2).

Awareness of own vaccination status

Older age, migrant background, ever had sex, having been to a gynaecologist and awareness of HPV were significantly associated with awareness of own vaccination status in univariate analyses. In multivariate analyses, only the variable having been to a gynaecologist remained statistically significant. Increased, but non-significant odds ratios were observed for the variables age and migrant background (table 3).

Self-reported vaccine uptake

In univariate analyses, only the variable ever been to a gynaecologist was significantly associated with self-reported vaccine uptake (OR 2.5; 95\% CI 1.37-4.53). A positive, nonsignificant association was observed for older age (OR 1.46; 95\% CI 0.82-2.59) (table 4). 


\section{Discussion}

Using data from a cross-sectional survey conducted among school-going adolescents in two German cities, we observed low awareness of HPV and of own vaccination status among female adolescents in the $8^{\text {th }}$ grade and above.

Only $9 \%$ of the participating girls positively answered all three items on awareness of HPV. Other than in previous studies conducted on HPV awareness we did not assess ever heard of HPV, awareness that HPV can cause cervical cancer and awareness of HPV vaccine separately, but instead combined the three items to form a comprehensive HPV awareness outcome. Although our results cannot be directly compared to previous findings, the low levels of awareness we observed, with only $23 \%$ of the pupils responding positively to that least two of the awareness items, are similar to those reported in other studies among school-going adolescents (Höglund et al. 2009; Gottvall et al. 2009; Agius et al. 2010; Marek et al. 2011). As this survey was conducted 4 years after the introduction of HPV vaccination in Germany, higher awareness of HPV was expected. This finding is an indication that information on HPV is not effectively reaching the vaccine target population of adolescent girls, especially those younger than 15 years old.

As commonly done in studies assessing vaccine uptake, studies estimating HPV vaccination rates generally rely on self-reported information (Marek et al. 2011; Blödt et al. 2011; Blumenthal et al. 2012). Adolescents may however not only underestimate HPV vaccination (Stupiansky et al. 2012), they may also not know whether or not they are vaccinated.

The fact that more than half of the girls surveyed did not know their vaccination status is disturbing as this appears to play an important role for awareness. Having been to a gynaecologist was significantly associated with all three outcome variables in univariate analyses, and with awareness of own vaccination status in multivariate analyses. It however cannot be ruled out, that some adolescents are being vaccinated without their knowledge on the request of their parents.

In a recent study of secondary school students in Australia, sexually active pupils did not exhibit better HPV knowledge (Agius et al. 2010). In our study, results of both univariate and multivariate analyses showed that pupils who had never had sex had less HPV awareness than those who were already sexually active.

Ethnic differences in awareness and knowledge of HPV which persist even after multivariate analyses have been reported in some studies (Walsh et al. 2008; Blödt et al. 2011; Marlow et al. 
2009; Das et al. 2010; Gelman et al. 2011). We observed significant associations between migrant background and awareness of HPV or of own vaccination status in univariate, but not in multivariate analyses.

To our knowledge, this is the first epidemiologic study reporting on awareness of HPV and of own vaccination status among school-going adolescent girls in Germany since the introduction of the vaccination in 2007. Participating schools were randomly selected and included both school forms offered in Bremen and Bremerhaven.

Our study has some weaknesses, one of which is the relatively low participation rate. We believe that parental conservatism towards the topic of survey may have played a role in reducing participation. Another limiting factor is the high number of unknown or missing data on parental education. This probably resulted in the apparent under-representation of mothers with low educational level.

The results on vaccine uptake have to be viewed with caution as the majority of the participants did not know whether or not they had been vaccinated and the possibility of under-reporting cannot be ruled out (Stupiansky et al. 2012). Furthermore, as we relied on self-reported information, we could not assess how many vaccine doses the girls had received.

In conclusion, our findings indicate that HPV prevention and vaccination information in Germany is not adequately reaching young adolescents. More research is needed to investigate factors contributing to unawareness of own HPV vaccination status among adolescents as these might have implications for health prevention and communication strategies.

Acknowledgements: We would like to thank Beate Schütte, Svea Eichholz, Sinja Ernst, Stefanie Helmer, Kathi Liegmann, Natalya Makarova, Anna Muschalek, Julia Nürnberg, Saskia Pöttgen and Sandra Wegeng for their support during the conduction of the survey in the schools. We especially thank the 8 schools in which we conducted the survey for their co-operation. 


\section{References:}

Agius PA, Pitts MK, Smith AM, Mitchell A. (2010). Human papillomavirus and cervical cancer: Gardasil vaccination status and knowledge amongst a nationally representative sample of Australian secondary school students. Vaccine, 28: 4416-4422

Blödt S, Holmberg C, Müller-Nordhorn J, Rieckmann N. (2011). Human papillomavirus awareness, knowledge and vaccine acceptance: A survey among 18-25 year old male and female vocational school students in Berlin, Germany. Eur J Public Health Dec 23. [Epub ahead of print]

Blumenthal J, Frey MK, Worley MJ Jr, Tchabo NE, Soren K, Slomovitz BM. (2012) Adolescent Understanding and Acceptance of the HPV Vaccination in an Underserved Population in New York City. J Oncol. 904034. Epub 2011 Dec 11

Das A, Madhwapathi V, Davies P, et al. (2010). Knowledge and acceptability of the HPV vaccine by school children and their parents in Birmingham. Vaccine, 28(6), 1440-6

Gelman A, Nikolajski C, Schwarz EB, Borrero S. (2011). Racial disparities in awareness of the human papillomavirus. J Women's Health , 20(8), 1165-1173. doi:10.1089/jwh.2010.2617

Gottvall M, Larsson M, Högkund AT, Tydén T. (2009). High HPV vaccine acceptance despite low awareness among Swedish upper secondary school students. Eur J Contr Repr Health Care , 14: $399-405$

Höglund AT, Tydén T, Hannerfors AK, Larsson M. (2009). Knowledge of human papillomavirus and attitudes to vaccination among Swedish high school students. Int J STD \& AIDS, 20: 102107

Klug SJ, Hetzer M, Blettner M. (2005). Screening for breast and cervical cancer in a large German city: participation, motivation and knowledge of risk factors. European Journal of Public Health, 15: 70-77 
Lenselink CH, Schmeink CE, Melchers WJG, et al. (2008). Young adults and acceptance of the human papillomavirus vaccine. Public Health , 122: 1295-1301

Limia A. (2011). Coverage of human papillomavirus vaccination during the first year of its introduction in Spain. Euro Surveill., 16(21):pii=19873.

http://www.eurosurveillance.org/ViewArticle.aspx?Articleid=19873 (Accessed 24.01.2012)

Marek E, Dergez T, Rebek-Nagy G, et al. (2011). Adolescents' awareness of HPV infections and attitudes towards HPV vaccination 3 years following the introduction of the HPV vaccine in Hungary. Vaccine, 29:8591-8598

Marlow LAV, Waller J, Wardle J. (2007). Public awareness that HPV is a risk factor for cervical cancer. British Journal of Cancer, 97: 691-694

Marlow LAV, Wardle J, Forster AS, Waller J. (2009). Ethnic difference in human papillomavirus awareness and vaccine acceptability. J Epidemiol Community Health, 63: 1010-1015.

Doi:10.1136/jech.2008.085886

Ogilvie GS, Remple VP, Marra F, et al. (2007). Parental intention to have daughters receive the human papillomavirus vaccine. CMAJ , 177: 506-521

Pelucchi C, Esposito S, Galeone C, et al. (2010). Knowledge of human papillomavirus infection and its prevention among adolescents and parents in the greater Milan area, Northern Italy. BMC Public Health, 10: 378

Sheridan A, White JL, Barlow T, Soldan K. (2010). Annual HPV vaccine uptake in England: 2008/09. London: Health Protection Agency, Department of Health. http://www.dh.gov.uk/prod_consum_dh/groups/dh_digitalassets/@dh/@en/@ps/documents/digi talasset/dh 111676.pdf (Accessed 24.01.2012)

Simoens C, Sabbe M, Van Damme P, Beutels P, Arbyn M. (2009). Introduction of human papillomavirus (HPV) vaccination in Belgium, 2007-2008. Euro Surveill., 14(46), pii=19407. http://www.eurosurveillance.org/ViewArticle.aspx?Articleid=19407 (Accessed 24.01.2012) 
Ständige Impfkommission (STIKO) am Robert Koch Institut. (2007). Impfung gegen humane Papillomaviren (HPV) für Mädchen von 12 bis 17 Jahren - Empfehlung und Begründung. Epidemiologisches Bulletin, 12: 97-103

Stupiansky NW, Zimet GD, Cummings T, Fortenberry JD, Shew M. (2012). Accuracy of selfreported human papillomavirus vaccine receipt among adolescent girls and their mothers. $\mathbf{J}$ Adolesc Health , 50(1),103-5

UNESCO. International Standard Classification of Education. (2010). www.uis.unesco.org. Walboomers JM, Jacobs MV, Manos MM, et al. (1999). Human papillomavirus is a necessary cause of invasive cervical cancer worldwide. J Pathol., 189 (1), 12-9

Walsh CD, Gera A, Shah M, Sharma A, Powell JE, Wilson S. (2008). Public knowledge and attitudes towards Human Papilloma Virus (HPV) vaccination. BMC Public Health,8:368.

Woodhall Sc, Lehtinen M, Verho T, Huhtala H, Hokkanen M, Kosunen E. (2007). Anticipated acceptance of HPV vaccination at the baseline of implementation: a survey of parental and adolescent knowledge and attitudes in Finland. J Adolesc Health, 40: 466-469

Zylka-Menhorn V, Meyer R. (2009). Humane Papillomaviren: In Deutschland wird spät geimpft. Dtsch Arztebl., 106(36), A-1713 / B-1474 / C-1442 
Table 1: Demographic and other characteristics of participants and distribution of reported awareness of HPV, of own vaccination status and of vaccine uptake by demographic and other characteristics of participants

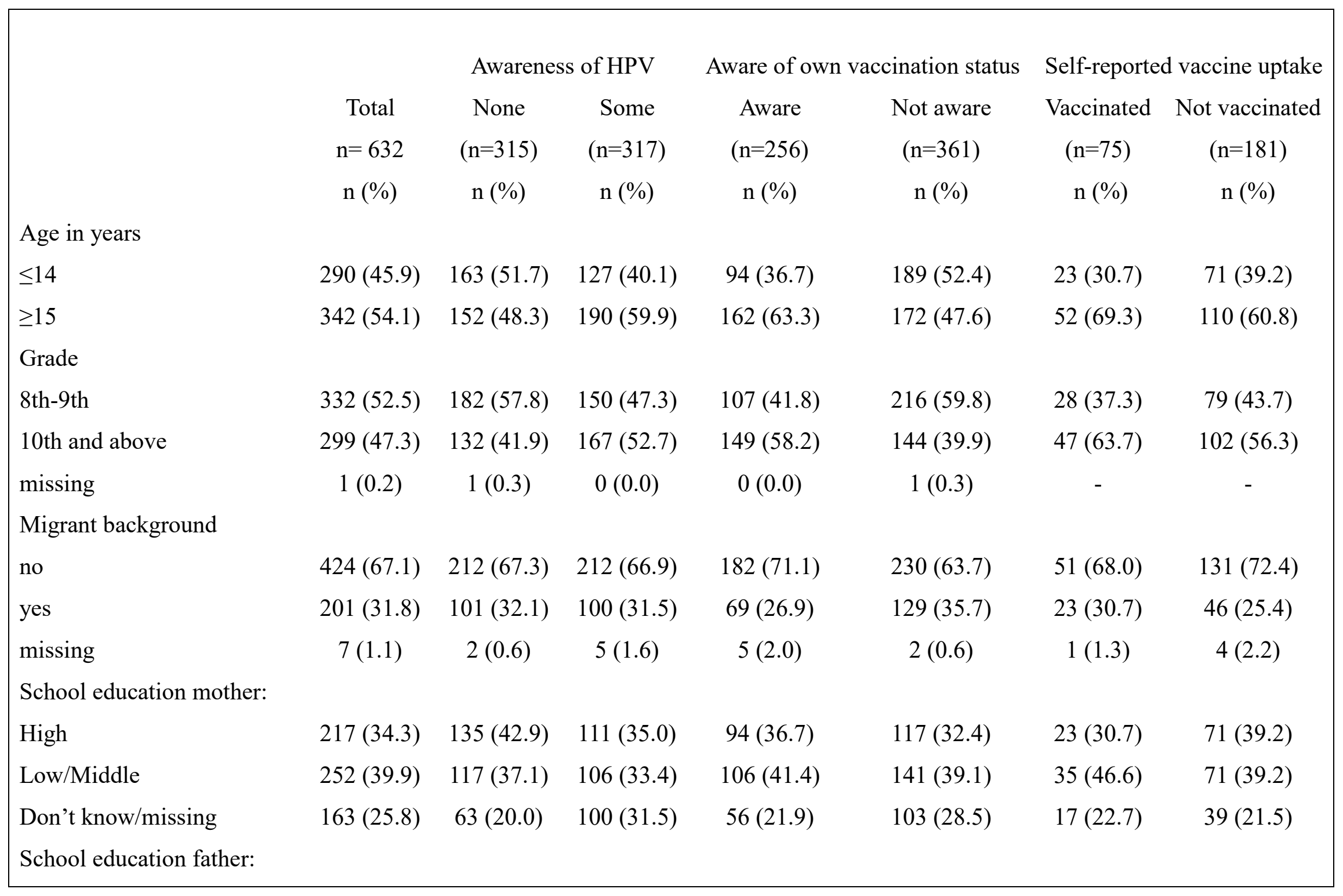




\begin{tabular}{|c|c|c|c|c|c|c|c|}
\hline High & $197(31.2)$ & $86(27.3)$ & $111(35.0)$ & $90(35.2)$ & $102(28.3)$ & $25(33.3)$ & $65(35.9)$ \\
\hline Low/Middle & $207(32.8)$ & $105(33.3)$ & $102(32.2)$ & $83(32.4)$ & $120(33.2)$ & $26(34.7)$ & $57(31.5)$ \\
\hline Don't know/missing & $228(36.1)$ & $124(39.4)$ & $104(32.8)$ & $83(32.4)$ & $139(38.5)$ & $24(32.0)$ & $59(32.6)$ \\
\hline \multicolumn{8}{|l|}{ Ever had sex } \\
\hline no & $466(73.7)$ & $253(80.3)$ & $213(67.2)$ & $166(64.8)$ & $289(80.1)$ & $44(58.7)$ & $122(67.4)$ \\
\hline yes & $162(25.6)$ & $60(19.0)$ & $102(32.2)$ & $89(34.8)$ & $69(19.1)$ & $31(41.3)$ & $58(32.0)$ \\
\hline missing & $4(0.6)$ & $2(0.6)$ & $2(0.6)$ & $1(0.4)$ & $3(0.8)$ & - & $1(0.6)$ \\
\hline \multicolumn{8}{|c|}{ Ever been to gynaecologist: } \\
\hline no & $311(49.2)$ & $170(54.0)$ & $141(44.5)$ & $102(39.8)$ & $203(56.2)$ & $19(25.3)$ & $83(45.1)$ \\
\hline yes & $316(50.0)$ & $141(44.8)$ & $175(55.2)$ & $154(60.2)$ & $153(42.4)$ & $56(74.7)$ & $9854.9)$ \\
\hline Don’t know/missing & $5(0.8)$ & $4(1.3)$ & $1(0.3)$ & - & $5(1.4)$ & - & - \\
\hline
\end{tabular}

Percentages not always adding to $100 \%$ due to rounding error 
Table 2: Results of univariate and multivariate analyses for association between independent variables and the outcome awareness of HPV comparing those with no awareness to those with some awareness (at least 1 item positively answered)

\begin{tabular}{|c|c|c|c|c|c|c|}
\hline & \multicolumn{3}{|c|}{ Univariate analyses } & \multicolumn{3}{|c|}{ Multivariate analyses } \\
\hline & $\mathrm{n}$ & OR & $95 \% \mathrm{CI}$ & $\mathrm{n}$ & OR & $95 \% \mathrm{CI}$ \\
\hline \multicolumn{7}{|l|}{ Age in years } \\
\hline$\geq 15$ & 342 & 1.60 & $1.17-2.20$ & 336 & 1.22 & $0.84-1.77$ \\
\hline$\leq 14$ (ref) & 290 & 1.00 & - & 288 & - & - \\
\hline \multicolumn{7}{|c|}{ School education of mother } \\
\hline High & 217 & 0.91 & $0.63-1.31$ & & & \\
\hline Low/Medium (ref) & 252 & 1.00 & - & & & \\
\hline \multicolumn{7}{|l|}{ Migrant background } \\
\hline no & 424 & 0.97 & $0.63-1.50$ & & & \\
\hline yes (ref) & 201 & 1.00 & - & & & \\
\hline \multicolumn{7}{|l|}{ Ever had sex } \\
\hline no & 466 & 0.56 & $0.36-0.86$ & 462 & 0.59 & $0.38-0.91$ \\
\hline yes(ref) & 162 & 1.00 & & 162 & 1.00 & - \\
\hline \multicolumn{7}{|c|}{ Ever been to gynaecologist } \\
\hline yes & 316 & 2.06 & $1.34-3.15$ & 315 & 1.11 & $0.77-1.61$ \\
\hline no (ref) & 311 & 1.00 & - & 309 & 1.00 & - \\
\hline
\end{tabular}

$\mathrm{OR}=$ odds ratio, $\mathrm{CI}=$ confidence interval, ref $=$ reference 
Table 3: Results of univariate and multivariate analyses for association between independent variables and the outcome awareness of own vaccination status

\begin{tabular}{|c|c|c|c|c|c|c|}
\hline & \multicolumn{3}{|c|}{ Univariate analyses } & \multicolumn{3}{|c|}{ Multivariate analyses } \\
\hline & $\mathrm{n}$ & OR & $95 \% \mathrm{CI}$ & $\mathrm{n}$ & OR & $95 \% \mathrm{CI}$ \\
\hline \multicolumn{7}{|l|}{ Age in years } \\
\hline$\geq 15$ & 334 & 1.89 & 1.37-2.63 & 233 & 1.46 & $0.98-2.16$ \\
\hline$\leq 14$ (ref) & 283 & 1.00 & - & 216 & 1.00 & - \\
\hline \multicolumn{7}{|c|}{ School education of mother } \\
\hline High & 211 & 1.07 & $0.74-1.55$ & & & \\
\hline Low/Medium (ref) & 247 & 1.00 & - & & & \\
\hline \multicolumn{7}{|l|}{ Migrant background } \\
\hline no & 256 & 1.48 & 1.04-2.10 & 313 & 1.36 & $0.94-1.95$ \\
\hline yes (ref) & 105 & 1.00 & - & 136 & 1.00 & - \\
\hline \multicolumn{7}{|l|}{ Ever had sex } \\
\hline no & 238 & 0.45 & $0.31-0.64$ & 343 & 0.73 & $0.47-1.15$ \\
\hline yes(ref) & 129 & 1.00 & & 106 & 1.00 & - \\
\hline \multicolumn{7}{|c|}{ Ever been to gynaecologist } \\
\hline yes & 307 & 2.00 & $1.45-2.78$ & 216 & 1.51 & 1.03-2.22 \\
\hline no (ref) & 305 & 1.00 & - & 233 & 1.00 & - \\
\hline
\end{tabular}

$\mathrm{OR}=$ odds ratio, $\mathrm{CI}=$ confidence interval, $\mathrm{ref}=$ reference 
Table 4: Results of univariate analyses for association between independent variables and the outcome self-reported vaccine uptake *

\begin{tabular}{|lccc|}
\hline \multicolumn{4}{c|}{ Univariate analyses } \\
& $n$ & OR & $95 \%$ CI \\
Age in years & & & \\
$\geq 15$ & 162 & 1.46 & $0.82-2.59$ \\
$\leq 14$ (ref) & 94 & 1.00 & - \\
School education of mother & & & \\
High & 94 & 0.66 & $0.35-1.22$ \\
Low/Medium (ref) & 106 & 1.00 & - \\
Migrant background & & & \\
no & 182 & 0.78 & $0.43-1.41$ \\
yes (ref) & 69 & 1.00 & - \\
Ever had sex & & & \\
no & 166 & 0.68 & $0.39-1.18$ \\
yes(ref) & 89 & 1.00 & - \\
Ever been to gynaecologist & & & \\
yes & 154 & $\mathbf{2 . 5 0}$ & $\mathbf{1 . 3 7 - 4 . 5 3}$ \\
no (ref) & 102 & 1.00 & - \\
\hline
\end{tabular}

* Multivariate analyses not done as only one variable was significantly associated with vaccine uptake in univariate analyses

$\mathrm{OR}=$ odds ratio, $\mathrm{CI}=$ confidence interval, ref $=$ reference 